\title{
AN ENERGY EFFICIENT STREET LIGHTENING SYSTEM BASED ON SOLAR ENERGY AND MPPT ALGORITHM
}

\author{
Sailee D. Sheldarkar ${ }^{1}$, Chhaya S. Khandelwal ${ }^{2}$ \\ ${ }^{1}$ ME Appeared, Electronics and Communication, Jawaharlal Nehru Engineering College (JNEC), Maharashtra, \\ India \\ ${ }^{2}$ Assistant Professor, Electronics and Communication, Jawaharlal Nehru Engineering College (JNEC), Maharashtra, \\ India
}

\begin{abstract}
The need for an energy sources is on the rise as the world is facing energy crisis and global warming. This paper suggests the system which makes an effective use of solar energy to drive the street lights. This system is consisting of $\langle i\rangle$ solar panel for the generation of electricity from the sun. <ii> Battery is used to store the generated electricity. 〈iii > In any solar application battery life is important therefore Maximum Power Point Tracker (MPPT) algorithm is used for the maximum power extraction from the panel as to increase the battery life. $<i v>$ Light Emitting Diodes (LED's) are used for lightening purpose instead of any other lamps $\langle v\rangle$ GSM is used here to provide the feedback regarding the status of street lights to the control room so that the corrective action could be taken. By implementing this system we can surely reduce the darkness on the streets without harming the environment as the system is eco-friendly.
\end{abstract}

Key Words: GSM, LDR, LED, MPPT, PWM.

\section{INTRODUCTION}

In the last years, the use of photovoltaic energy is increased as it is the renewable energy source and it enhances the electric grid reliability. Hydro- electricity and thermal electricity are the main source of electricity. Thermal electricity is produced by the burning of fossil fuels, more importantly coal. Burning of coal is having great potential to pollute the environment hence responsible for global warming. So, it is good to cut off some loads from the electric grid. One of those loads is street lights. The complete street lighting system can be run on the PV system. Any PV system mainly depends on the storage buffer. In some PV systems the battery accounts for more than $40 \%$ of the life cycle costs [1]. Battery life can be increased by avoiding deep discharging and over charging of the battery. To accomplish this task the maximum power point tracker (MPPT) algorithm is implemented. MPPT is the technique used to transfer the maximum possible power from solar panel to the load i.e. in our case battery. The essence of MPPT algorithm is buck convertor. Maximum power point is a product of maximum power point voltage and maximum power point current. In this system LED's are used for the lighting purpose. However the recent technology is improving gradually the light emitting diodes efficiency and color quantity, which allows their application in lighting system [2]. To reduce the energy consumption study of each component matters hence the LED is the best option available. The feedback regarding the status of street lights are given to the control room via GSM in terms of message(s). if somehow any street light is remain of during night time the alert message of that particular street light will be send to the control room and thus the corrective action can be taken. To replace the all conventional street lighting system following factors should be taken into account: 1) Lamp which is to be replaced 2) Human vision response.

\subsection{Lamp which is to be replaced}

To develop the solar based street lighting system to reduce the energy consumption study of each component matters. Lamp in any street lighting system plays an important role. There are several types of lamps are available for installation in the systems. These lamps are High Pressure Mercury (HPM), High Pressure Sodium (HPS), Low Pressure Sodium (LPS), Metal Halide (MH) and Light Emitting Diode (LED). In conventional street lightening system mostly MH and HPS lamps are used. As the growing development in the LED it can be considered as promising light source. There are two different options to save energy in case of lamps: changing the standards and changing the technology; for example, the British Standard BS5489 allows reducing the required lighting class when the Color Rendering Index (CRI) of the lamp is higher than $60 \%$ (white light)[3].

\subsection{Human Vision Response}

To develop a proper street lighting system it is mandatory to take the consideration regarding the human eye response to the light. Human eye reacts to the light. Photoreceptors (i.e. light sensors) are located at the back surface of the human eye. This area is called the retina. The surface of the retina is composed of both rods ( 120 million) and cones ( 7 million). Rods and cones are the primary means through which the eye receives images and translates optical signals that are transferred to the brain [4]. The rods and cones are 
the photoreceptor cells which are responsible for the detection of light in various lightening conditions. The rods cells are responsible for vision in low light conditions called scotopic vision. The cone cells are responsible for vision in normal lightening conditions called photopic vision. The scotopic and photopic human sensitivity were considered in [4] and shown that the 70W high pressure sodium lamp can be replace by the 20 LEDs with 145 1m @ 700 MA gives the same light illuminations.

\section{PROPOSED SYSTEM}

Lightening system has great relevance in power saving strategies, techniques for rational use of energy and energy efficiency [5].Thus the optimized and economical lightening system based on solar and LEDs is presented in fig. 1

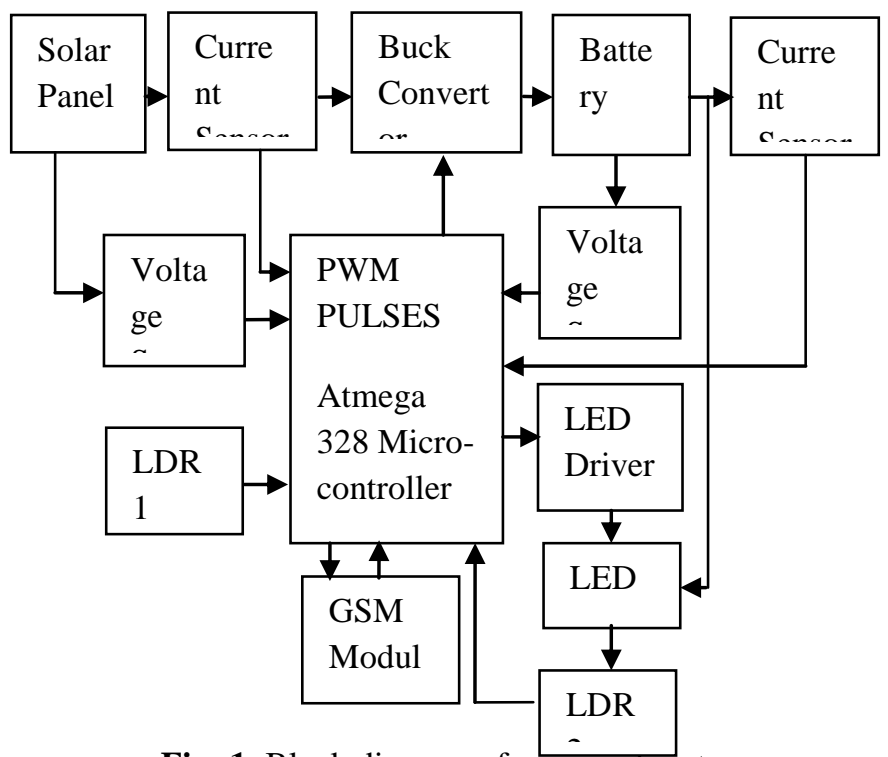

Fig -1: Block diagram of proposed system

In this system the Atmega 328 microcontroller is used to provide the PWM signals which are necessary for the implementation of the MPPT algorithm. Atmega 328 controller is having six PWM channels. The shown system is independent of utility grid. The output of the solar panel is given to buck convertor. A buck convertor is used to step down the voltage and step up the current. For the implementation of MPPT algorithm buck convertor is mandatory. The output of the buck convertor is given to the battery. For the MPPT algorithm controller gets the total four inputs. First two inputs are the voltage and the current of the solar panel and the rest of the inputs are the voltage and the current of the battery. According to the status of voltages and currents the controller generates the PWM signals. These generated PWM signals are given to the buck convertor for the controlled charging of the battery. As the proposed system is automatic i.e. street lights will turn on when there is a dim lightening condition and will turn off when there is sufficient light. To know the lightening conditions LDR1 is used. According the status of LDR 1 the controller will take the action for whether to turn on the street lights or not. If any street light remains off during the night time the system will alert the controller room via
GSM. In the same way if any street light is on during the day time system will again alert the control room. To recognize whether the street light is on or off LDR2 is used.

\subsection{Buck Convertor}

The basic configuration of buck convertor is shown in the following figure. Buck convertor is simple DC-DC convertor.

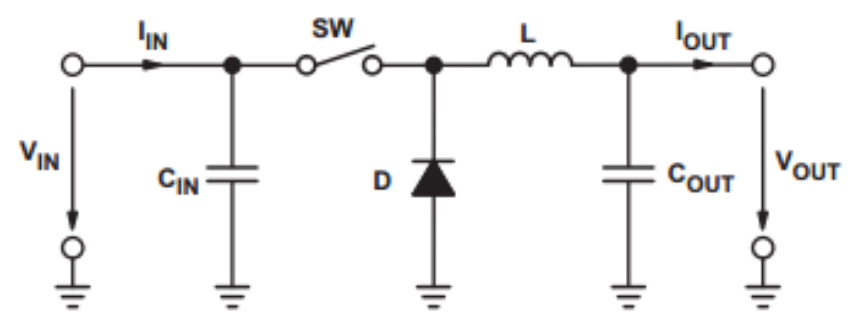

Fig -2: Buck Convertor

When the power is taken into the consideration step down or buck convertors are widely used.

\subsection{Results}

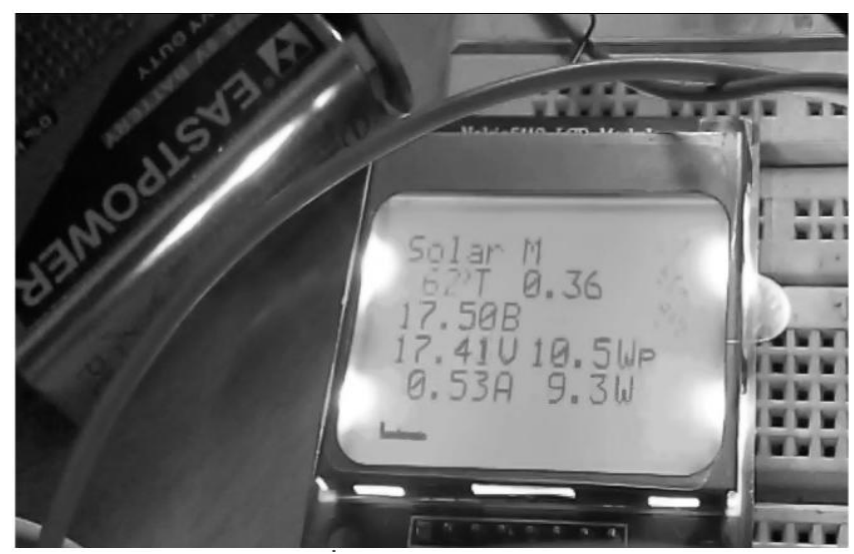

Fig -3: Result Display

The results which are shown in the following table are taken with the solar panel which is having rating of $10 \mathrm{~W}$. The MPPT algorithm which is implemented here almost gives the maximum power that is shown in the table.

Table -1: Results Highlighted text value is where MPPT is achieved.

\begin{tabular}{|c|c|c|}
\hline $\begin{array}{c}\text { Panel } \\
\text { Voltage (V) }\end{array}$ & $\begin{array}{c}\text { Panel current } \\
\text { (amp) }\end{array}$ & $\begin{array}{c}\text { Panel Power } \\
\text { (watt) }\end{array}$ \\
\hline 17.43 & 0.48 & 8.41 \\
\hline 17.37 & 0.41 & 7.12 \\
\hline 17.41 & 0.53 & 9.3 \\
\hline 17.01 & 0.46 & 7.8 \\
\hline 16.98 & 0.3 & 5.09 \\
\hline
\end{tabular}




\section{CONCLUSIONS}

By implementing this paper we can reduce the darkness on the streets at a great extend using solar power. This system is independent of utility grid and it is a closed loop system. It uses maximum solar power to charge the battery. MPPT technique optimizes battery charging and increases the battery life. As all the power stages are DC-to-DC, thus the efficiency is increase and such kind of conversion yields an easy implementation and control. The system is based on solar energy it has great potential to reduce the pollution in the environment. It does not produce any hazardous gases to generate the electricity. In future this system will play an important role to construct the smart cities. The feedback may be provided by the Wi-Fi devices instead of GSM.

\section{ACKNOWLEDGEMENT}

The Authors gratefully thank Jawaharlal Nehru Engineering College (JNEC), Aurangabad, Maharashtra, India, for providing the platform for intended work done. We would also like to thank our classmates and team mates for being the pillar of our inspiration.

\section{REFERENCES}

[1] Juan Manuel Carrasco, Jan T. Bialasiewicz, Ramon C. Portillo Guisa do Jose Ignacio Leon, "Power Electronics System for the Grid Integreation of Renewable Energy Sources: A Survey", IEEE Trans.Industrial Electronics, vol-53, no 4, pp10021016, Aug 2006.

[2] Shane Duryea, Syed Islam, William Lawrance, "A Battery Management System for Stand Alone Photovoltaic Energy Systems", 0-7803-5589X/99/\$10.00 @ 1999 IEEE.

[3] Alberto Gutierrez-Escolar, Ana Castillo- Martinez, Jose M. Gmez-Pulido, Jose-Maria Guiterrez- Martinez, Zalkto Stapic, "A Study to Improve the Quality of Street Lighting in Spain", Energies 2015,8,976-994,doi: 10.3390/en8020976

[4] M.A.Dalla Costa, L. Schuch, L.Michels, C.Rech, J.R.Pinherio, G.H. Costa*, "Autonomous Street Lighteing System Based on Solar Energy and LED's", 978-1-4244-5697-0/10/\$25.00@2010 IEEE.

[5] Somchai Hiranvaroom, "A Comparative Analysis of Photovoltaic Street Lighting System Installed in Thailand", $3^{\text {rd }}$ World Conf. Photovoltaic Energy Conversion Osaka, Japan,2003,pp-2478-2481.

\section{BIOGRAPHIES}

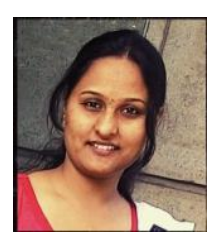

Sailee D.Sheldarkar has completed her diploma in Electronics and Communication from Hi-Tech Polytechnic, Aurangabad in 2010 and done B.E (ECT). degree from Deogiri College of Engineering, Aurangabad, India in 2013. Currently pursuing masters in Electronics from Jawaharlal Nehru Engineering College, Aurangabad, India.

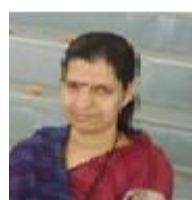

Chhaya S. Khandelwal has done B.E. (ECT) from M. S. Bidve College of Engineering in 1991. Completed M.E. Electronics from Govt. College of Engineering, Aurangabad in 2001 and having 17 years of teaching experience. Member of IETEITE and QCFY. 